\title{
Right to food for people seeking asylum: A statement from the asylum seeker resource centre
}

\author{
Chantelle Bazerghi* \\ ASRC Foodbank Manager, Footscray, VIC 3011, Australia
}

\begin{abstract}
People seeking asylum are at a high risk of experiencing food insecurity due to restricted access to income support and the right to work, often resulting in limited or no income. A recent study of the Asylum Seeker Resource Centre (ASRC) Foodbank clearly indicated that food insecurity for people accessing this service was due to a partial or complete lack of financial means to purchase food. It is therefore crucial that all people seeking asylum in Australia have access to Government-funded income support and are able to work while their claims are being assessed to ensure the Right to Food becomes a reality for the many that are currently going without.
\end{abstract}

\section{Statement}

Food insecurity exists when a community does not have the physical and financial means to access nutritionally adequate and safe foods, or when the ability to access food in socially acceptable ways is limited or uncertain [1-3]. Food insecurity is most often due to a lack of financial resources, low level of food preparation skills and nutritional education, limited availability of healthy and culturally appropriate foods, lack of mobility, lack of transportation and homelessness [4-6].

Additionally, those who experience food insecurity tend to consume less fresh food and more energy dense foods [4,7], increasing the risk of poor mental health, obesity and chronic disease [8,9]. According to the Victorian Department of Human Services, 'poor nutrition accounts for up to 10 percent of the total burden of disease in Australia' (2006, p. 20 ), not including the significant health costs associated with diabetes [10].

Food insecurity affects around five percent of the Australian population [11] and the number of people requiring food aid in Australia due to food insecurity has increased in recent years [12], with food banks being one of the most common food aid services utilised. Food banks (or food pantries) are typically run by charitable and notfor-profit organisations, which collect donated and purchased grocery items and redistribute them directly to those in need [13].

This is a growing concern among public health physicians and those working in the sector as equitable access to food for all Australians and those under our protection are not being adequately addressed by governments and thereby supplemented by charities $[14,15]$. This is of greatest concern for populations most affected by food insecurity in Australia such as those with low socioeconomic status, indigenous populations and newly arrived populations, including those seeking asylum [16].

Currently, there are approximately 10,000 people seeking asylum in the community in Victoria [17] and tend to experience food insecurity at higher levels than other vulnerable groups [18]. This is due to the dual negative effects of temporary visa restrictions and limited work rights, often resulting in limited or no income as many are ineligible for income support [19]. Subsequently, for many people seeking asylum in the Melbourne region, the Asylum Seeker Resource Centre (ASRC) Foodbank is their main source of weekly food.

A study commissioned by the ASRC and published in 2015 [20] found that $90 \%$ of people seeking asylum who visit the ASRC Foodbank Program were food insecure and had run out of food in the previous week. A further $42 \%$ reported weight loss since arriving in Australia because they did not have enough food to eat and $40 \%$ had gone to bed hungry. There were no statistically significance links between level of food security and gender, age, level of education, health status, household size, and distance from the Foodbank or region of origin [20]. These results clearly indicate that food security for people seeking asylum is due to a partial or complete lack of financial means to purchase food.

If all people seeking asylum in Australia, regardless of their visa type, had access to government-funded income support and were able to work while their claims were being assessed then Australia would be much closer to realising the Right to Food for this vulnerable group. The ASRC recommends these changes to the current legislation be seriously considered if Australia intends to remain signatory to the Refugee Convention and uphold the Universal Declaration of Human Rights, which includes the Right to Food. Equitable access to food also has the potential to mitigate some of the negative physical and mental health costs associated with food insecurity that impact on our community, both financially and socially [21], making it of great benefit to the community at large.

While food insecurity remains a complex and multifaceted issue affecting a variety of population groups across Australia, the opportunity to take effective and life changing measures to improve

Correspondence to: Chantelle Bazerghi, ASRC Foodbank Manager, A: Level 1, 218 Nicholson St, Footscray, VIC 3011, Australia, Tel: 03-9326-6066; E-mail: chantelle.b@asrc.org.au

Keywords: right to food, asylum seeker, food security, work rights, Australia, foodbank, food pantry

Received: June 07, 2016; Accepted: June 27, 2016; Published: June 30, 2016 
access to food should be acted upon wherever possible. The Right to Food is a human right [2], whether you are a human who is Australian by birth, through migration or from seeking refuge. People seeking asylum do not need to remain food insecure while they await their visa outcomes, which can take several years and result in chronic illhealth for years to come $[22,23]$. We have obligations both locally and internationally to protect those in our care within our means [24], and in this day and age of plenty, ensuring access to food should certainly be within our means.

\section{References}

1. Gany F, Bari S, Crist M, Moran A, Rastogi N (2013) Food insecurity: limitations of emergency food resources for our patients.Journal of Urban Health: Bulletin of the New York Academy of Medicine 90: 552-8.

2. Food \& Agriculture Organization of the United Nations (2016)About right to food, United Nations.

3. Remley DT, Claudia ZA, Carmen LM, Melgar QH, Chris T (2010) Spanish- and English-Speaking Client Perceptions of Choice Food Pantries. Journal of Hunger \& Environmental Nutrition 5: 120 .

4. Gorton D, Bullen CR, Mhurchu CN (2010) Environmental influences on food security in high-income countries. Nutr Rev 68: 1-29. [Crossref]

5. Loopstra R, Tarasuk V (2012) The Relationship between Food Banks and Household Food Insecurity among Low-Income Toronto Families.Canadian Public Policy 38: 497-514.

6. Whiting SJ, Vatanparast H, Taylor JG, Adolphe JL (2010) Barriers to healthful eating and supplement use in lower-income adults. Canadian Journal of Dietetic Practice and Research 71: 70-6.

7. Kirkpatrick SI, Tarasuk V (2008) Food insecurity is associated with nutrient inadequacies among Canadian adults and adolescents. J Nutr 138: 604-612. [Crossref]

8. Australian Institute of Health and Welfare (2012) Australia's food \& nutrition 2012. Cat. no. PHE 163. Canberra, AIHW.

9. Holben DH (2012) Food bank users in and around the lower mainland of British Columbia, Canada, are characterized by food insecurity and poor produce intake. Journal of Hunger \& Environmental Nutrition 7: 449-58.
10. Handforth B, Hennink M, Schwartz MB (2013) A qualitative study of nutrition-based initiatives at selected food banks in the feeding America network. J Acad Nutr Diet 113: 411-415. [Crossref]

11. Foodbank Australia (2013) End Hunger in Australia Report 2013, Foodbank.

12. Diggins A (2010) More Hunger, More Waste - A Report on the Experiences of Emergency Food Relief Agencies in Melbourne and Hobart in 2009, SecondBite.

13. Lambie-Mumford H (2013) Every Town Should Have One: Emergency Food Banking in the UK, Journal of Social Policy 42: 73-89.

14. Bazerghi C, McKay FH, Dunn M (2016) The Role of Food Banks in Addressing Food Insecurity: A Systematic Review.J Community Health. [Crossref]

15. Shields R (2016) Food alone will not end hunger. Parity 29: 16-17.

16. Lindberg R, Lawrence M, Gold L, Friel S, Pegram O (2015) Food insecurity in Australia: Implications for general practitioners Australian Family Physician 44: 859-862.

17. Department of Health \& Human Services (2016) Refugee and asylum seeker health and wellbeing, Department of Health \& Human Services.

18. O'Reilly S, O'Shea T, Bhusumane S (2012) Nutritional vulnerability seen within asylum seekers in Australia. J Immigr Minor Health 14: 356-360. [Crossref]

19. Piwowarczyk, L, Keane T, Lincoln A (2008) Hunger: The Silent Epidemic Among Asylum Seekers and Resettled Refugees. International Migration 46: 59-77.

20. McKay F, Dunn M (2015) Food security among asylum seekers in Melbourne, Australian and New Zealand. Journal of Public Health.

21. Public Health Association of Australia (2012) Policy-at-a-glance- Food, Nutrition and Health Policy.

22. Vincenzo R, Crotty P, Burns C, Rozman M, Ballinger M, et al. (2000) Easing the transition: food and nutrition issues of new arrivals. Health Promotion Journal of Australia: Official Journal of Australian Association of Health Promotion Professionals 10: 230 .

23. Stuff JE, Casey PH, Connell CL, Champagne CM, Gossett JM, et al. (2006) Household Food Insecurity and Obesity, Chronic Disease, and Chronic Disease Risk Factors. Journal of Hunger \& Environmental Nutrition 1: 43-62.

24. Australian Human Rights Commission (2015) Asylum seeker and refugees guide, Australian Human Rights Commission.

Copyright: (C2016 Bazerghi C. This is an open-access article distributed under the terms of the Creative Commons Attribution License, which permits unrestricted use, distribution, and reproduction in any medium, provided the original author and source are credited. 